\title{
Originals
}

\section{Application of prazosin is associated with an increase of insulin sensitivity in obese patients with hypertension}

\author{
T. Pollare', H. Lithell' ${ }^{1}$, I.Selinus ${ }^{1}$ and C. Berne ${ }^{2}$ \\ Departments of ${ }^{1}$ Geriatrics and ${ }^{2}$ Internal Medicine, Uppsala University, Uppsala, Sweden
}

\begin{abstract}
Summary. The aim of this study was to determine whether insulin sensitivity measured by the euglycaemic insulin clamp technique is lower in patients with primary hypertension than in matched healthy control subjects, and whether this sensitivity was affected after 12 weeks of antihypertensive treatment with the alpha 1-adrenoceptor blocking drug prazosin. Twelve moderately obese normoglycaemic patients (four men), with hypertension not previously treated with pharmacological agents and diastolic blood pressure above $100 \mathrm{~mm} \mathrm{Hg}$, and 12 healthy matched control subjects participated. Supine blood pressure decreased $12 / 5 \mathrm{~mm} \mathrm{Hg}(p<$ $0.01)$ and standing blood pressure $14 / 9 \mathrm{~mm} \mathrm{Hg}(p=0.001)$ during prazosin treatment (mean dosage $5.3 \pm 1.6 \mathrm{mg} /$ day (SD)). During euglycaemic insulin clamp studies the control subjects showed a higher mean glucose uptake than the untreated hypertensive patients $(7.5 \pm 1.0$ and $5.8 \pm 1.9 \mathrm{mg} \cdot \mathrm{kg}$ b. w. ${ }^{-1} \cdot \min ^{-1}$, respectively, $\left.p<0.01\right)$. During prazosin treatment there was no significant difference between the hyper-
\end{abstract}

tensive patients and the control subjects in this respect (6.6 \pm 2.8 and $7.5 \pm 1.0$, respectively, $p=0.21$ ). During prazosin treatment, however, the disappearance rate of glucose decreased during the intravenous glucose tolerance test (from $1.7 \pm 0.9$ to $1.3 \pm 0.6, p<0.02$ ) and the area under the glucose concentration-time curve decreased by $38 \%$ (from $473 \pm 119$ to $294 \pm 99, p<0.001)$. The peak insulin concentration decreased from $55 \pm 35$ to $46 \pm 32 \mathrm{mU} / 1 \quad(p<0.006)$ and the area under the insulin concentration-time curve was suppressed by $38 \%$ (from $2368 \pm 1597$ to $1479 \pm 940, p<0.01$ ). This study shows that treatment of moderately obese hypertensive patients with prazosin is associated with an increase of the insulin-mediated glucose disposal and a decrease of the insulin response to an intravenous glucose load.

Key words: Glucose tolerance, hypertension, insulin sensitivity, lipids, prazosin.
Obesity is often associated with a decreased sensitivity to insulin, hyperinsulinaemia and a diminished number of insulin receptors [1-3]. In obese persons with elevated blood pressure the plasma insulin concentration is increased, a change which is independent of age, weight and blood glucose level [4]. Insulin may be an important factor in the regulation of blood pressure in obese subjects $[3,5]$ by its direct effect on renal sodium retention and/or through increased sympathetic nervous system activity [6-8]. There are also indications that tissue insulin resistance may enhance peripheral vascular resistance by altering the internal sodium and potassium distributions $[9,10]$. Decreased insulin sensitivity and hyperinsulinaemia might be the mechanism linking glucose intolerance, obesity, and hypertension [10,11]. After weight reduction in obese patients, a parallel decrease in basal hyperinsulinaemia, sympathetic nervous system activity and blood pressure takes place [12].
In a previous study [13] we found that treatment of hypertension with the alpha 1-adrenoceptor blocking drug prazosin reduced the early insulin response in otherwise healthy hypertensive women.

The aim of this study was to determine whether insulin sensitivity, measured with the euglycaemic insulin clamp technique, is lower in patients with primary hypertension than in matched healthy control subjects; and furthermore, whether this sensitivity was changed during the application of prazosin treatment for hypertension.

\section{Subjects and methods}

\section{Subjects}

Twelve moderately obese patients (four men) were recruited (Table 1) from a health screening survey in Uppsala, Sweden. Their diastolic blood pressure consistently exceeded $100 \mathrm{~mm} \mathrm{Hg}$ (after at 
Table 1. Characteristics of the hypertensive and control groups. Mean values and standard deviations for age, weight, body mass index (BMI), fasting plasma glucose and insulin, $k$ value during intravenous glucose tolerance test (IVGTT), supine systolic (SBP) and diastolic blood pressure (DBP) and heart rate (HR). The $p$ values for the hypothesis of equal group means are presented

\begin{tabular}{|c|c|c|c|}
\hline & $\begin{array}{l}\text { Hyper- } \\
\text { tensive } \\
\text { patients }\end{array}$ & $\begin{array}{l}\text { Normo- } \\
\text { tensive } \\
\text { subjects }\end{array}$ & $p$ value \\
\hline Number & 12 & 12 & \\
\hline $\operatorname{Sex}(M / F)$ & $4 / 8$ & $4 / 8$ & \\
\hline Age (years) & $58 \pm 8$ & $56 \pm 13$ & 0.19 \\
\hline Weight $(\mathrm{kg})$ & $78 \pm 15$ & $76 \pm 11$ & 0.18 \\
\hline $\operatorname{BMI}\left(\mathrm{kg} / \mathrm{m}^{2}\right)$ & $28 \pm 4$ & $28 \pm 3$ & 0.31 \\
\hline Fasting plasma glucose $(\mathrm{mmol} / \mathrm{l})$ & $5.3 \pm 0.6$ & $5.3 \pm 0.5$ & 0.21 \\
\hline Fasting plasma insulin $(\mathrm{mU} / \mathrm{l})$ & $8.4 \pm 5.8$ & $6.1 \pm 3.5$ & 0.038 \\
\hline $\mathrm{k}$ value $\left(\% \min ^{-1}\right)$ & $1.7 \pm 0.9$ & $1.7 \pm 0.6$ & 0.41 \\
\hline SBP supine $(\mathrm{mm} \mathrm{Hg})$ & $174 \pm 18$ & $131 \pm 13$ & $<0.001$ \\
\hline DBP supine $(\mathrm{mm} \mathrm{Hg})$ & $106 \pm 6$ & $77 \pm 11$ & $<0.001$ \\
\hline HR supine (beats/min) & $73 \pm 9$ & $67 \pm 7$ & 0.030 \\
\hline
\end{tabular}

least two bi-weekly blood pressure measurements) despite advice to try to reduce their intake of refined carbohydrates and sodium during 3-4 months. After this no other dietary prescription was given. Their mean age was 57 years, ranging from 47 to 70 . Four were smokers. They were moderately obese with an average body mass index (BMI) of $28.2 \pm 4.0$ (SD). Furthermore, they were free of other diseases, as determined by case history and thorough physical examination, and had not been treated with any drugs. There was no clinical or laboratory evidence of hepatic, renal or thyroid dysfunction. All had normal fasting plasma glucose concentrations and $\mathrm{HbA}_{1 \mathrm{C}}$ values. Twelve age-, weight-, and sex-matched, healthy volunteers, recruited from the Uppsala area, served as a control group (Table 1). Informed consent was obtained from all subjects after the nature, purpose and possible side-effects of the study had been fully explained. The study protocol was approved by the Human Ethics Committee of the Medical Faculty of Uppsala University.

\section{Drug treatment}

Before treatment the patients came twice to the Department of Geriatrics for metabolic investigation after an overnight fast. The hypertensive patients were then given prazosin, $0.5 \mathrm{mg}$ twice a day for one week, after which the dose was increased weekly by $1 \mathrm{mg} /$ day until blood pressure was adequately controlled or disturbing side-effects occurred. After 12 weeks the average prazosin dose was $5.3 \pm$ $1.6 \mathrm{mg} /$ day and the metabolic investigations were repeated. All tests were carried out in the morning without prior intake of prazosin on that day. Blood pressure was measured by a nurse with a mercury sphygmomanometer, three times in the supine position after a rest of $10 \mathrm{~min}$, and twice after $1 \mathrm{~min}$ standing. The mean of the measurements was used. A large cuff was used when appropriate. The pulse rate was recorded before each blood pressure measurement. Compliance with drug treatment was assessed in all patients by interview and pill count. Side effects were actively investigated by means of a questionnaire.

\section{Metabolic investigations}

The insulin response to an intravenous glucose tolerance test (IVGTT) and insulin sensitivity were evaluated on two separate days. Each participant was instructed to adhere to a diet rich in carbohydrates (at least $250 \mathrm{~g}$ of carbohydrates daily) and to refrain from extreme physical exercise or inactivity for at least five days beforc the investigation. No other dietary or exercise instructions were given during the study. Blood samples were drawn and urine was collected after an overnight fast.
An IVGTT was performed, with injection of $300 \mathrm{mg} / \mathrm{kg}$ body weight (b.w.) of glucose in a $50 \%$ glucose solution within $1.5 \mathrm{~min}$. Venous blood samples were taken at $-10,-5,0,2,4,6,8$ and $10 \mathrm{~min}$ in relation to the start of the glucose injection and then every $10 \mathrm{~min}$ up to $90 \mathrm{~min}$, for insulin and glucose measurements. Plasma glucose was measured by the glucose oxidase method (KabiVitrum, Stockholm, Sweden). The disappearance rate of glucose was expressed as a $k$ value calculated from the formula $k=100^{e} \log 2 / T^{1 / 2} ; T^{1 / 2}$, the time $(\mathrm{min})$ required to halve the glucose concentration, was determined from the best fit of the measured values on semilogarithmic paper [14]. A $\mathrm{k}$ value of more than 1.0 was considered normal. Immunoreactive insulin was assayed in plasma, using a commercial radioimmunoassay kit (Phadeseph Insulin RIA, Pharmacia, Uppsala, Sweden). The peak insulin response was defined as the mean of the values obtained at 2,4 and $6 \mathrm{~min}$. The areas under the curve for glucose and insulin during IVGTT were calculated as the deviations from the basal value integrated over the sampling time. The average fasting plasma insulin concentration was calculated from samples taken on two separate days. $\mathrm{HbA}_{1 \mathrm{C}}$ was measured by fast performance liquid chromatography (normal range 3.5-6.0\%) [15].

Triglyceride and cholesterol concentrations in serum and lipoproteins were determined by enzymatic methods (Boehringer/Mannheim, Mannheim FRG) in a Multistat III F/LS (Instrumentation Laboratories, Lexington, Mass, USA). The analytical errors for the two methods were 1.4 and $1.7 \%$, respectively. Very-low-density lipoproteins (VLDL) were separated by ultracentrifugation at a density of 1.006. A magnesium chloride/phosphotungstate acid technique was applied to precipitate low-density lipoproteins (LDL) from the bottom fraction after ultracentrifugation [16]. The supernatant (highdensity lipoprotein, HDL) was analysed for its contents of triglyceride and cholesterol. HDL subclass 3 was separated from other lipoproteins by ultracentrifugation of serum at a density of 1.120 . The cholesterol and triglyceride concentrations were measured in $\mathrm{HDL}_{3}$ (density $>1.120$ ) and the contents of these lipids in $\mathrm{HDL}_{2}$ were calculated as the difference between those in total HDL and $\mathrm{HDL}_{3}$. The lipid concentrations in LDL were calculated as the difference between those in the bottom fraction after ultracentrifugation at a density of 1.006 and those in HDL.

BMI was calculated as weight (in $\mathrm{kg}$ ) divided by height squared (in meters).

\section{Insulin sensitivity studies}

The euglycaemic hyperinsulinaemic clamp technique was used to estimate in vivo sensitivity to insulin, before and after 12 weeks of prazosin treatment. The control group was studied once. The technique has been described in detail by DeFronzo et al. [17], and only the general procedure will therefore be outlined here.

One hand and forearm were placed in a plexiglass box which was thermoregulated at $65^{\circ} \mathrm{C}$. Two polytetrafluorethylene cannulae (Venflon, Viggo, Helsingborg, Sweden) were positioned intravenously, one in an antecubital vein for all infusions and a second one, inserted retrogradely and distally, in a vein of the other arm to obtain arterialised venous blood $\left(\mathrm{PaO}_{2}>85 \mathrm{~mm} \mathrm{Hg}\right)$ [18]. Basal samples were not taken until 40 min after cannulation. Semisynthetic regular human insulin (Actrapid Human, Novo, Copenhagen, Denmark) was infused in a priming dose for the first $10 \mathrm{~min}$ and then as a continuous infusion for $110 \mathrm{~min}$ to maintain steady state hyperinsulinaemia. The insulin infusion rate was $56 \mathrm{mU} / \mathrm{m}^{2}$ per $\mathrm{min}$ in all subjects, resulting in a mean plasma insulin concentration of $91 \mathrm{mU} / 1$ (range $71-115 \mathrm{mU} / \mathrm{l}$ ).

The chosen level of plasma glucose during the clamp study was the fasting concentration and this was maintained by measuring the plasma glucose every $5 \mathrm{~min}$ and adjusting the rate of infusion of the $20 \%$ glucose solution accordingly. Plasma was immediately separated in a Beckman microfuge and plasma glucose was assayed in duplicate in a Beckman Glucose Analyzer II (Beckmann Instruments, Fullerton, Calif, USA). There was no significant $(p>0.5)$ difference in the group mean steady-state plasma glucose concentration 
during the clamp study (Table 2). The coefficient of variation for the steady-state plasma glucose concentration for a single clamp was < $4.5 \%$ on all occasions, reflecting the maintenance of steady-state plasma glucose levels throughout the glucose clamp study. Despite the standardised procedure, there was a tendency towards lower steady-state insulin concentrations in the second test $(87 \pm 22 \mathrm{mU} / 1)$ than in the first one $(99 \pm 28 \mathrm{mU} / \mathrm{l})(p=0.08)$ (Table 2$)$.

\section{Calculations of insulin sensitivity}

Steady-state plasma glucose and plasma insulin concentrations were calculated as the mean of all values obtained between the 20th and 120 th min of the clamp study. The total amount of glucose infused serves as a measure of the subject's sensitivity to the prevailing plasma insulin concentrations. The glucose uptake during the glucose clamp was calculated on the basis of the amount of glucose infused and is expressed per $\mathrm{kg}$ body weight. The amount of glucose taken up (mg. $\left.\mathrm{kg} \mathrm{b} . \mathrm{w}^{-1} \cdot \mathrm{min}^{-1}\right)$ during each study was calculated for each 20 -min interval after the initial $20 \mathrm{~min}$ of the study. The mean glucose uptake rate for the last $100 \mathrm{~min}$ of the clamp was used as the main target variable for that individual study. The insulin sensitivity index (the amount of glucose metabolised per unit of plasma insulin, $\mathrm{mg} \cdot \mathrm{kg} \mathrm{b} \cdot \mathrm{w}^{-1} \cdot \mathrm{min}^{-1}$ per $\mathrm{mU} / 1$ multiplied by 100 ) is a measure of the tissue sensitivity to insulin expressed per unit insulin and was calculated by dividing the mean glucose uptake by the mean insulin concentration during the same period of the clamp [17]. The calculation of the total body insulin sensitivity is based on the assumption that endogenous hepatic glucose production is entirely suppressed. Under euglycaemic conditions it is known that almost $90 \%$ of this production is suppressed when the plasma insulin concentration is increased by $50 \mathrm{mU} / 1$. The insulin levels (about $91 \mathrm{mU} / 1$ ) attained during the insulin infusion in our study have been reported to be sufficient to suppress hepatic glucose production, also in hypertensive subjects, to a negligible production rate even in the presence of insulin resistance [19-24]. Urinary glucose losses were negligible under euglycaemic conditions. As an aid to comparisons of insulin sensitivities in subjects with differing plasma glucose levels, the metabolic clearance rate of glucose $\left(\mathrm{ml} \cdot \mathrm{kg} \mathrm{b} . \mathrm{w}^{-1} \cdot \mathrm{min}^{-1}\right)$ was calculated by dividing the mean glucose uptake by the mean steady-state glucose concentration for each 20 -min interval. When the glucose concentration is almost the same on the different test occasions, as in this study, the levels of and changes in both glucose uptake and the metabolic clearance rate of glucose will differ only in scale $[25,26]$, by definition.

\section{Statistical analysis}

Data are presented as means $\pm \mathrm{SD}$ and, in the figures, as means \pm SEM. The hypothesis of equal pretreatment and per-treatment means was tested for the reported variables in a two-way analysis of variance model (equal to Student's paired two sample $t$-test if the data were balanced). The factors in the model were patient and time point. Correlation coefficients are Pearson product-moment correlations. The significance of the mean difference between the hypertensive and control group was determined by Student's paired two-sample t-test.

\section{Results}

Blood pressure, in both the supine and standing position, decreased significantly $(p<0.01)$ during prazosin treatment (Table 3 ). The mean reductions at the end of the therapeutic period were 12 and $5 \mathrm{~mm} \mathrm{Hg}$ for the supine systolic and diastolic blood pressures, respectively, and 14 and $9 \mathrm{~mm} \mathrm{Hg}$ for the corresponding pressures in the standing position. Heart rate increased sig-
Table 2. Steady-state plasma insulin and glucose concentrations and coefficient of variation for glucose during the clamp studies. Mean glucose uptake and insulin sensitivity index during the last $100 \mathrm{~min}$ of the clamp study in 12 healthy control subjects and 12 hypertensive patients before and during ( $>90$ days) prazosin treatment. During prazosin treatment there was no significant difference $(p>0.17)$ compared with control subjects. Data are expressed as mean \pm SD

\begin{tabular}{|c|c|c|c|}
\hline & $\begin{array}{l}\text { Control } \\
\text { subjects }\end{array}$ & $\begin{array}{l}\text { Untreated } \\
\text { hypertensive } \\
\text { patients }\end{array}$ & $\begin{array}{l}\text { During } \\
\text { prazosin } \\
\text { treatment }\end{array}$ \\
\hline $\begin{array}{l}\text { Steady-state plasma } \\
\text { insulin }(\mathrm{mU} / \mathrm{l})\end{array}$ & $84 \pm 19$ NS & $99 \pm 28 \quad \mathrm{NS}$ & $87 \pm 22$ \\
\hline $\begin{array}{l}\text { Steady-state plasma } \\
\text { glucose }(\mathrm{mmol} / \mathrm{l})\end{array}$ & $5.3 \pm 0.5 \mathrm{NS}$ & $5.3 \pm 0.7 \mathrm{NS}$ & $5.2 \pm 0.6$ \\
\hline $\begin{array}{l}\text { Coefficient of variation } \\
(\%) \text { for glucose }\end{array}$ & $3.5 \pm 0.6 \mathrm{NS}$ & $3.4 \pm 0.9 \mathrm{NS}$ & $3.3 \pm 0.9$ \\
\hline $\begin{array}{l}\text { Mean glucose disposal } \\
\text { during the last } 100 \mathrm{~min} \\
\left(\mathrm{mg} \cdot \mathrm{kg} \mathrm{b} . \mathrm{w}^{-1} \cdot \mathrm{min}^{-1}\right)\end{array}$ & $7.5 \pm 1.0^{h}$ & $5.8 \pm 1.9^{a}$ & $6.6 \pm 2.8$ \\
\hline
\end{tabular}

Statistically significant changes: ${ }^{\mathrm{a}} p<0.05,{ }^{\mathrm{b}} p<0.01$, NS $=$ not significant

Table 3. Mean values and standard deviations for systolic (SBP) and diastolic (DBP) blood pressure, heart rate (HR), and body weight (BW) in 12 hypertensive patients before and during treatment with prazosin. The $p$ values for the hypothesis of equal means over time are given.

\begin{tabular}{lrcl}
\hline & $\begin{array}{l}\text { Before } \\
\text { treatment }\end{array}$ & $\begin{array}{l}\text { During } \\
\text { prazosin } \\
\text { treatment } \\
\text { (>90 days) }\end{array}$ & $p$ value \\
\hline SBP, supine (mm Hg) & $174 \pm 18$ & $163 \pm 18$ & 0.0054 \\
DBP, supine (mm Hg) & $106 \pm 6$ & $101 \pm 7$ & 0.0006 \\
HR, supine (beats $/ \mathrm{min})$ & $73 \pm 9$ & $75 \pm 10$ & 0.029 \\
SBP, standing (mm Hg) & $169 \pm 16$ & $155 \pm 18$ & 0.0001 \\
DBP, standing (mm Hg) & $110 \pm 7$ & $101 \pm 6$ & 0.0001 \\
HR, standing (beats/min) & $78 \pm 8$ & $83 \pm 9$ & 0.0012 \\
BW (kg) & $78 \pm 15$ & $78 \pm 15$ & 0.24 \\
\hline
\end{tabular}

nificantly $(p<0.05)$ both in the supine and standing position (Table 3 ).

The plasma glucose and insulin responses to the IVGTT before and after three months of prazosin treatment are shown in Figures $1 \mathrm{a}$ and $\mathrm{b}$. The $\mathrm{k}$ value of the IVGTT decreased during prazosin treatment (from $1.7 \pm 0.9$ to $1.3 \pm 0.6, p<0.02$ ). There was no change in $\mathrm{HbA}_{1 \mathrm{C}}(5.0 \pm 0.4$ and $5.0 \pm 0.5 \%$, respectively) but a slightly significant decrease (from $5.3 \pm 0.6$ to $5.1 \pm 0.5 \mathrm{mmol} / 1, p<0.03$ ) of fasting plasma glucose occurred. The area under the glucose concentrationtime curve decreased significantly by about $38 \%$ during IVGTT (from $473 \pm 119$ to $294 \pm 99, p<0.001$ ). Treatment with prazosin resulted in a highly significant decrease in the glucose-stimulated insulin concentrations, whereas the fasting insulin concentrations were not altered $(8.4 \pm 5.8 \mathrm{mU} / 1$ before and $7.9 \pm 6.2$ after, $p=0.61$ ). Compared to the matched control subjects there was a significantly increased fasting insulin con- 

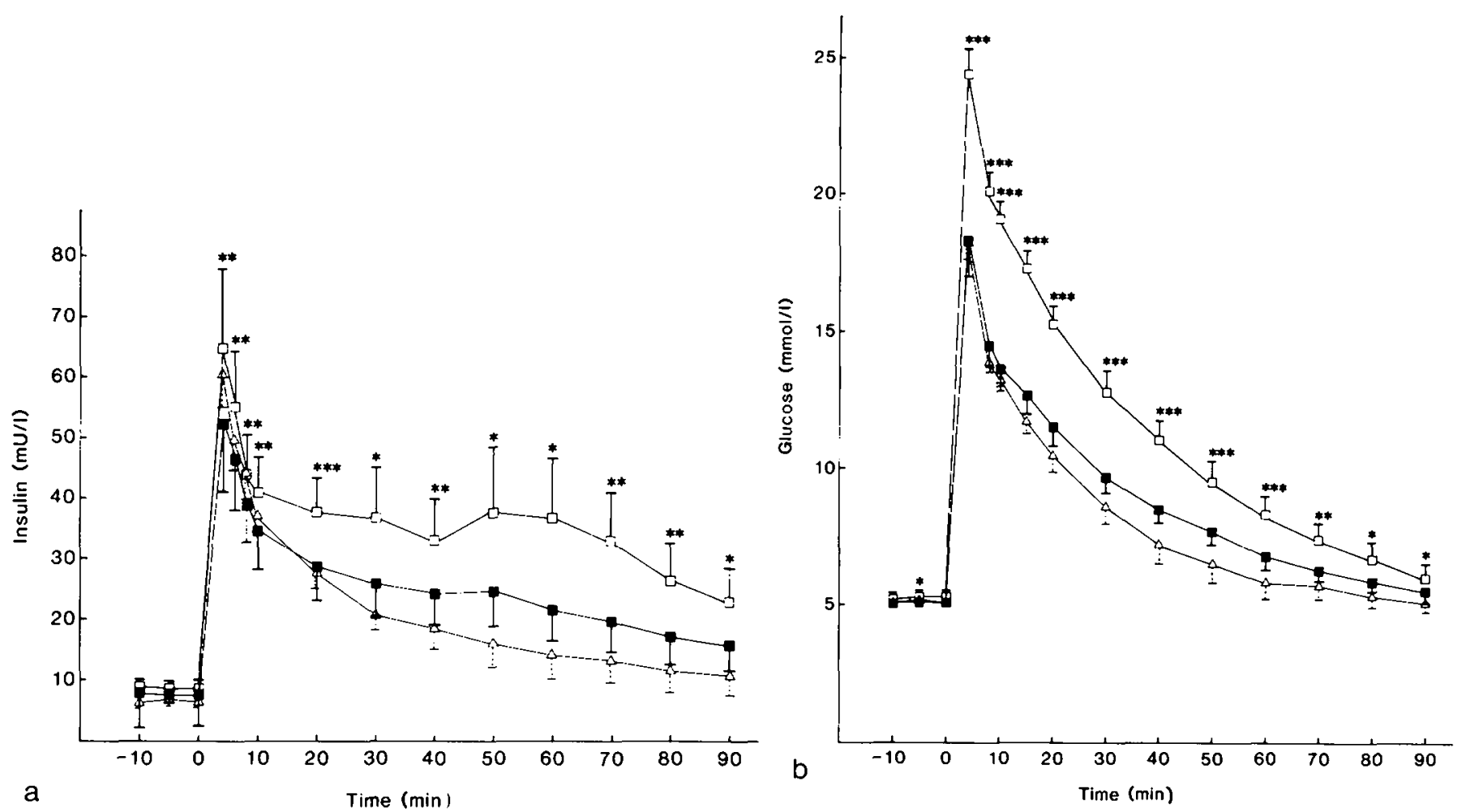

Fig. 1. The plasma insulin (a) and glucose (b) reponses (mean \pm SEM) during an intravenous glucose tolerance test in 12 hypertensive patients and 12 matched healthy control subjects. Open squares ( $\square$ ), before treatment; closed squares ( $\square$ ), during prazosin treatment ( $>90$ days); open triangle $(\Delta)$, control subjects. Statistically significant changes for each time point, before and during prazosin treatment, are indicated by asterisks: ${ }^{*}=p<0.05,{ }^{* *}=p<0.01,{ }^{* * *}=p<0.001$. The plasma insulin and glucose responses in untreated hypertensive patients were significantly higher than those in the control group at all time points $(p<0.01)$

centration in the untreated hypertensive patients $(p<$ $0.05)$. The area under the insulin concentration-time curve from 0 to 90 min was decreased by about $38 \%$ $(2368 \pm 1597$ before and $1479 \pm 940$ after, $p<0.01)$. The peak insulin value was significantly lowered from $55 \pm 35$ to $46 \pm 32 \mathrm{mU} / \mathrm{l}(p<0.006)$.

The insulin sensitivity as assessed by the glucose clamp was higher (as compared with the initial clamp value) after treatment during each 20 -min period $(4.2 \pm 1.1$ and $5.3 \pm 3.1 ; 5.5 \pm 2.4$ and $6.3 \pm 3.4 ; 6.1 \pm 2.0$ and $6.7 \pm 2.8 ; 6.4 \pm 2.1$ and $6.9 \pm 2.4 ; 6.5 \pm 2.1$ and $7.6 \pm 2.4)$. The mean glucose uptake during the last $100 \mathrm{~min}$ of the first clamp was $5.8 \pm 1.9 \mathrm{mg} \cdot \mathrm{kg}$ b. w. $^{-1} \cdot \mathrm{min}^{-1}$, compared with $6.6 \pm 2.8$ during the second clamp $(p<0.05)$. Metabolic clearance rate of glucose during the last $100 \mathrm{~min}$ showed similar changes $\left(6.3 \pm 2.6\right.$ and $7.2 \pm 3.9 \mathrm{ml} \cdot \mathrm{kg} \mathrm{b} . \mathrm{w}^{-1} \cdot \mathrm{min}^{-1}$, respectively, $p<0.05)$.

The insulin sensitivity index for the last $100 \mathrm{~min}$ of the clamp showed significantly increased insulin sensitivity $(6.6 \pm 3.8$ and $8.8 \pm 6.7 ; p<0.03)$. As seen in Table 2, the age-, weight-, and sex-matched control subjects were found to have a significantly higher mean glucose uptake during the last 100 min than the untreated hypertensive patients $(7.5 \pm 1.0$ and $5.8 \pm$ $1.9 \mathrm{mg} \cdot \mathrm{kg} \mathrm{b} . \mathrm{w}^{-1} \cdot \mathrm{min}^{-1}$, respectively, $p=0.005$ ). During prazosin treatment there was no significant differ- ence between the hypertensive patients and the control subjects in this respect $(6.6 \pm 2.8$ and $7.5 \pm 1.0$, respectively, $p=0.21$ ).

The serum cholesterol and triglyceride levels in the HDL, LDL and VLDL subfractions were not significantly modified by the drug treatment.

Adverse clinical effects occurred in four patients: one person had an attack of postural dizziness. Two persons showed ankle oedema. One person had palpitations during the first day and experienced light nasal congestion.

\section{Discussion}

In the measurements of in vivo insulin sensitivity, we found that before treatment our hypertensive group had a significantly lower glucose uptake, by about $23 \%$, than the matched healthy control group. These findings support the hypothesis that essential hypertension is an insulin-resistant state in its own right [11]. Recently these observations were confirmed by Ferrannini et al. who reported that insulin resistance is confined to nonoxidative pathways of glucose disposal in peripheral tissue and furthermore, does not involve the liver [24]. During prazosin treatment the glucose uptake was significantly improved by $14 \%$. 
Glucose uptake is an effect of the hyperinsulinaemic state and is directly related to the prevailing insulin concentration. It is therefore worthy of note that despite lower steady-state plasma insulin levels during the second clamp (during treatment) the glucose uptake was significantly increased and the degree of improvement in insulin sensitivity was, if anything, underestimated. The index for tissue sensitivity to insulin which probably better estimates the degree of improvement under these circumstances was 33\% higher during prazosin treatment than before.

Treatment with prazosin also resulted in a highly significant decrease in the glucose-stimulated insulin response and the area under the insulin concentrationtime curve. This might be an effect of circulating norepinephrine on the alpha 2-adrenoceptors of the $B$ cells or of increased insulin sensitivity, which primarily acts to decrease the late insulin response $[13,27$, 28]. The area under the glucose concentration-time curve also decreased significantly. Despite this, the $\mathrm{k}$ value was significantly decreased, as in our previous study [13], probably as a result of the decreased insulin peak values. The increased distribution (plasma) volume observed in some studies [29-31] during prazosin treatment may have contributed to the lower plasma glucose and insulin peak values during IVGTT. This was a short-term study, but we have previously observed that the effects of prazosin on plasma insulin and glucose tolerance are unchanged during a period of up to one year [13].

In some studies $[32,33]$ treatment with prazosin has been found to be associated with a decrease in serum triglycerides and cholesterol, but in the present study the tendency towards lower values did not reach statistical significance. It cannot be excluded that the reported effects on serum lipids may have been secondary to the decreased plasma insulin concentration during prazosin treatment.

The blood pressure response to prazosin was moderate in the supine position, but more pronounced while standing, and might be due to the moderate dose prescribed during this study $(5.3 \mathrm{mg} /$ day) or to fluid retention. After completion of the study half of the patients required addition of a second drug to achieve adequete blood pressure reduction.

The mechanism underlying the effects of prazosin on glucose and insulin concentrations is not clear, but it may be speculated that relaxation of systemic arteriolae increases the blood flow through muscle tissues $[34,35]$ and thereby improves the tissue response to glucose and insulin; however, it cannot be excluded that the increase in insulin-mediated glucose disposal is in some way related to the lowering of blood pressure. There was no significant $(p=0.35)$ correlation between change in blood pressure and change in insulin sensitivity. There was, however, a positive correlation $(r=0.59)$ between improvement of insulin sensitivity and an increase in heart rate during prazosin treatment $(p<0.05)$. The increase in heart rate may better reflect the increase in blood flow and vasodilatation caused by prazosin than the reduction in blood pressure. Recently the vasodilatation caused by the ACE inhibitor captopril was found to be associated with an improvement of insulin sensitivity in non-insulin-dependent diabetic patients [36].

Our results show that treatment of moderately obese hypertensive patients with prazosin is associated with an increase of the insulin-mediated glucose disposal and a decrease of the insulin response to an intravenous glucose load.

Acknowledgement. This work was supported by the Swedish Medical Research Council (grant 5446), the Swedish National Association against Heart and Lung Diseases and "Förenade Liv" Mutual Group Life Insurance Company, Stockholm, Sweden.

\section{References}

1. Kahn CR (1980) Role of insulin receptors in insulin-resistant states. Metabolism 29: 455-466

2. Olefsky JM (1981) Insulin resistance and insulin action. An in vitro and in vivo perspective. Diabetes 30: 148-162

3. Reaven GM (1980) Insulin-independent diabetes mellitus: metabolic characteristics. Metabolism 29: 445-451

4. Lucas CP, Estigarribia JA, Darga LL, Reaven GM (1985) Insulin and blood pressure in obesity. Hypertension 7: 702-706

5. Berglund G, Larson B, Andersson O, Larsson O, Svärdsudd K, Björntorp P, Wilhelmsen L (1976) Body composition and glucose metabolism in hypertensive middle-aged males. Acta Med Scand 200: 163-169

6. DeFronzo RA (1981) The effect of insulin on renal sodium metabolism. Diabetologia 21: 165-171

7. Rowe JW, Young JB, Minaker KL, Stevens AL, Pallotta J, Landsberg L (1981) Effect of insulin and glucose infusions on sympathetic nervous system activity in normal man. Diabetes 30 : 219-225

8. Basarab A, Silva P, Landsberg L (1979) Effect of catecholamines on tubular function in the isolated perfused rat kidney. J Clin Invest $64: 850-857$

9. Winquist RJ, Webb RC, Bohr DF (1982) Vascular smooth muscle in hypertension. Fed Proc 41: 2387-2393

10. Modan M, Halkin H, Almog S, Lusky A, Eshkol A, Shefi M, Shitrit A, Fuchs Z (1985) Hyperinsulinemia; a link between hypertension, obesity and glucose intolerance. J Clin Invest 75 : 809-827

11. Manicardi V, Camelline L, Bellodi G, Coscelli C, Ferrannini E (1986) Evidence for an association of high blood pressure and hyperinsulinemia in obese man. J Clin Endocrinol Metab 62: 1302-1304

12. Sowers JR, Nyby M, Stern N, Beck F, Baron S, Catania R, Vlachis $N$ (1982) Blood pressure and hormone changes associated with weight reduction in the obese. Hypertension 4: 686-691

13. Lithell H, Berne C, Waern U, Wibell L (1985) Glucose metabolism during long-term treatment with prazosin. Diab Res 2: 297-299

14. Ikkos D, Luft $R$ (1957) On the intravenous glucose tolerance test. Acta Endocr (Kbh) 25: 312-334

15. Jeppsson JO, Jerntorp P, Sundkvist G, Englund H, Nylund V (1986) Measurement of hemoglobin $\mathrm{A}_{1} \mathrm{C}$ by a new liquid-chromatographic assay: methodology, clinical utility, and relation to glucose tolerance evaluated. Clin Chem 32: 1867-1872

16. Siegler L, Wu WT (1981) Separation of serum high-density lipoprotein for cholesterol determination: ultracentrifugation vs precipitation with sodium phosphotungstate and magnesium chloride. Clin Chem 27: 838-841 
17. DeFronzo RA, Tobin JD, Andres R (1979) Glucose clamp technique: a method for quantifying insulin secretion and resistance. Am J Physiol 237: 214-233

18. McGuire EAM, Helderman JH, Tobin JD, Andres R, Berman M (1976) Effects of arterial versus venous sampling. An analysis of glucose kinetics in man. J Appl Physiol 41: 565-573

19. Bratusch-Marrain PR, Smith D, DeFronzo RA (1982) The effect of growth hormone on glucose metabolism and insulin secretion in man. J Clin Endocrinol Metab 55: 973-982

20. Rizza RA, Mandarino LJ, Gerich JE (1981) Mechanism and significance of insulin resistance in non-insulin dependent diabetes mellitus. Diabetes 30: 990-995

21. Rizza RA, Mandarino LJ, Gerich JE (1981) Dose-response characteristics for effects of insulin on production and utilization of glucose in man. Am J Physiol 240: E630-E639

22. Bergman RN, Finegood DT, Ader M (1985) Assessment of insulin sensitivity in vivo. Endocr Rev 6: 45-86

23. DeFronzo RA, Ferrannini E, Hendler R, Felig P, Wahren J (1983) Regulation of splanchnic and peripheral glucose uptake by insulin and hyperglycemia in man. Diabetes $32: 35-45$

24. Ferrannini E, Buzzigoli G, Bonadonna R, Giorico MA, Oleggini M, Graziadei L, Pedrinelli R, Brandi L, Bevilacqua S (1987) Insulin resistance in essential hypertension. N Engl J Med 317 350-357

25. Doberne L, Greenfield MS, Rosenthal M, Widstrom A, Reaven $G$ (1982) Effect of variations in basal plasma glucose concentration on glucose utilization (M) and metabolic clearance (MCR) rates during insulin clamp studies in patients with non-insulindependent diabetes mellitus. Diabetes 31: 396-400

26. Liu G, Chen I, Hollenbeck CB, Lardinois CK, Reaven GM (1984) Insulin-stimulated glucose disposal increases with time in patients with non-insulin-dependent diabetes mellitus. Diabetes 33: $643-647$

27. Nakaki T, Nakadate T, Kato R (1980) Alpha 2 -adrenoceptors modulating insulin release from isolated pancreatic islets. Naunyn Schmiedebergs Arch Pharmacol 313: 151-153

28. Nakadate T, Nakaki T, Muraki T, Kato R (1980) Adrenergic regulation of blood glucose levels: possible involvement of postsyn- aptic alpha 2 -type adrenergic receptors regulating insulin release. J Pharmacol Exp Ther 215: 226-230

29. Scharf SC, Lee H-B, Wexler JP, Blaufox MD (1984) Cardiovascular consequences of primary antihypertensive therapy with prazosin hydrochloride. Am J Cardiol 53: 32A-36A

30. Koshy MC, Mickley D, Bourgoignio J, Blaufox MD (1977) Physical evaluation of a new antihypertensive agent: prazosin $\mathrm{HCL}$. Circulation 55: 533-537

31. Ibsen H, Rasmussen K, Jensen HA, Leth A (1978) Changes in plasma volume and extracellular fluid volume after addition of prazosin to propranolol treatment in patients with hypertension. Scand J Clin Lab Invest 38: 425-429

32. Leren P, Foss OP, Helgeland A, Holme I, Lund-Larsen PG (1980) Effect of propranolol and prazosin on blood lipids. The Oslo Study. Lancet II: 4-6

33. Lowenstein J, Neusy A-J (1984) Effects of prazosin and propranolol on serum lipids in patients with essential hypertension. Am J Med 76: 79-84

34. Waldo R (1979) Prazosin relieves Raynaud's vasospasm. JAMA 241: 1037

35. Westheim A, Koss A, Sivertssen E (1986) Hemodynamic effects at rest and during exercise in long-term treatment witzh prazosin in chronic congestive heart failure. Acta Med Scand 219: 449-453

36. Jauch KW, Hartl W, Guenther B, Wicklmayr M, Rett K, Dietze $G$ (1987) Captopril enhances insulin responsiveness of forearm muscle tissue in non-insulin-dependent diabetes mellitus. Eur $\mathbf{J}$ Clin Invest 17: 448-454

Received: 16 October 1987

and in revised form: 11 May 1988

Dr. T. Pollare

Department of Geriatrics

Uppsala University

POB 12042

S-750 12 Uppsala

Sweden 